\title{
Musings on the current state of COVID-19 modeling and reporting
}

\author{
Peter L. Bonate ${ }^{1}$ \\ Published online: 29 May 2020 \\ (C) Springer Science+Business Media, LLC, part of Springer Nature 2020
}

In thinking about the current state of COVID-19-related modeling I am reminded of the Rime of the Ancient Mariner. Samuel Taylor Coleridge wrote "water, water, every where, nor any drop to drink." Today its "models, models every where, which one to believe." Every day COVID-19 related models are reported in the newspapers and on the television. Model predictions have become an everyday topic of conversation in households and among coworkers. People have become armchair modelers or critics. Models are often chosen to support a political narrative. There comes a point with having more and more models, those predictions have less and less value. Here are some musings I've had on the current state of COVID-19 Modeling and Reporting.

- How many different models are there for COVID-19 transmission dynamics? I think you would be hard pressed to know exactly. The website for the Centers for Disease Control and Prevention (CDC) uses 12 different models for their predictions of COVID-19 related deaths [1]. I like this website for several reasons. Not only do they report predictions for each model, they use ensemble modeling to make a collective 2-week prediction into the future. They don't report how the ensemble was done, perhaps it was as simple as an average, but they do try to account for the many different models. I also like that they report 95\% prediction intervals. Too many scientists confuse confidence intervals and prediction intervals and it's nice to see that the CDC gets it right.

- Twenty years ago, when spreadsheets were first starting to be used, there was concern that because of their ease of use, scientists were inappropriately and possibly misusing statistics to obtain the results they desired, i.e., $\mathrm{p}<0.05$. Programs like Excel or Minitab made it far to

Peter L. Bonate

Peter.Bonate@astellas.com

1 Astellas Pharma, Northbrook, IL, USA easy for anyone to push a button and generate a statistic and a p-value. Spreadsheets removed the critical thinking around whether the statistic you are using is appropriate and whether the assumptions behind that statistic are met. It looks like this concern also applies to modeling. In these times it seems everyone is a modeler. In the last week, two stories have come into the news. The first relates to a graphic used by the Georgia Department of Health showing that the number of new coronavirus cases declined every day for the last 2 weeks in five counties with the most infections. A close examination by reporters revealed that the dates of the graph were not sorted in chronological order and the graph was a grievous error [2]. The Department of Health claimed it was a mistake, not purposeful, and I believe them. It's far too easy for amateurs to use the graphics capability of Excel to make graphs any way they want without having to think about whether what they are doing is correct.

- Related to this was a story shortly thereafter which reported that the White House was making claims related to the number of COVID-19 deaths using a model developed by Kevin Hassett of the Council of Economic Advisors. Hassett showed that deaths would drop to zero by May 15, which is great news if true [3]. The problem is that Hassett used a cubic polynomial, which is easily implemented in Excel, to fit the observed data and then extrapolated into the future to predict when the number of COVID deaths would be zero. Every modeler knows that extrapolation is always risky and working with polynomials is especially risky for many reasons. In this case, had he extrapolated beyond May 15 he would have seen that the predicted number of COVID deaths was negative, an impossibility, and that his model was wrong (don't get me started on all models are wrong; that's another commentary). Hassett says he was just "smoothing the data" and he probably was. The problem again goes back to the ease of statistics and graphics functions in spreadsheets which takes the critical thinking of modeling out of the equation (no pun intended). 
- Today I was reading in the New York Times an article that reported that lockdown delays cost an additional 36,000 lives [4]. Had the lockdowns started sooner more lives would have been saved seems obvious. The Times reported that on May 3 a total of 65,307 reported deaths were due to coronavirus. Had social distancing started just 1 week earlier that number would be 29,410 deaths and had it started 2 weeks earlier that number would be 11,253 deaths. When I read this, I thought "those are oddly specific numbers." Not 29,411 or 11,254 , but 29,410 and 11,253 to be exact. And that's the problem with newspaper reports. This story was based on a paper from Sen Pei and colleagues from Columbia University using a modified SEIR model of six large metropolitan areas [5]. Pei et al. reported that had observable countermeasures been taken a week earlier, the US would have avoided 35,927 deaths with a $95 \%$ confidence interval of 30,088 to 40,638 . The confidence intervals are not reported in the Times story. They never are. When predictions are reported in the news, the error associated with those predictions are never reported. All scientists know that predictions are not made with absolute certainty but reporting predictions without that uncertainty gives those predictions a level of credibility that they do not have. I am not picking on the Times; all newspapers are guilty of this. To be fair, the Times goes on to say that "All models are only estimates, and it is impossible to know for certain the exact number of people who would have died." But this caveat was buried at the end of the story and many casual readers might not even have noticed it or gotten that far to read it. There are a couple of other issues related to this article that bear worth mentioning. First, just how many significant figures are needed for death counts? I am not an expert in this area, but five significant figures seem too many to me. This seems an unacceptable level of precision. There is a phenomenon in psychology where experts that report percentages as $\mathrm{x} . \mathrm{x} \%$ are deemed more credible than experts that just report $x \%$. I would argue that a prediction of 29,410 is deemed more believable than a prediction of 29,400 (which seems more reasonable using a smaller number of significant figures). The second aspect relates to the title of this article, which was "Lockdown delays cost at least 36,000 lives, data show." I think it wrong to have said "data show". I personally do not believe that models are data. Models are built from data. Data are observable phenomenon. A more correct title would have been to use "predictions show" or "models show."

- Suddenly groups that operated in relative obscurity are now celebrities. Did you know there was an Institute for Disease Modeling funded by the Bill and Melinda Gates
Foundation? I didn't, at least not before the pandemic. As scientists we are thought of as impartial, but we are also human and subject to the kind of vanity as others. There is a lot at stake here. Sure, most people go into science because they want to better the world, but there is also recognition and money (grants, books, etc.) at stake. Modelers are being interviewed by reporters and being presented on television to discuss their models having their own $15 \mathrm{~min}$ of fame. There is a huge incentive to get the work released first rather than being first and correct. Preprint services like MedRxiv do a service by publishing potentially important articles that could benefit society, but they are not subject to peer review. Reporters routinely report from these preprints as if they had been reported in peer-reviewed journals [4]. This opens the door for potentially flawed work to be accepted [6]. Flawed models decrease the credibility of other models opening the door to criticisms that models are "simply unreliable." [7].

- I think there are important implications for COVID-19 modeling outside of modeling pandemic related statistics and that relates to climate change. Let's not forget that climate change predictions, many of which are dire, are based on models. Using models to drive policy change during the pandemic sets precedence for using models to drive policy change with climate change. And by corollary, discrediting pandemic models leads to bystander model discrediting in the climate change arena. Hence, opponents to climate change have a genuine stake in discrediting pandemic models as well.

Where does all this leave us, as citizens of the world? As modelers? I recognize that reporters can't state the assumptions behind all the models they report nor do most laypeople know what a confidence interval is, let alone a prediction interval (hell, a lot of modelers don't even know the difference), but I do think we can do better to educate people. As I stated in my commentary in the last issue, we have an opportunity here. This time we have an opportunity to improve quantitative literacy in society. For the first time, people are interested in modeling and models. We've used modeling in weather prediction for decades, but most people don't seem to care about the science or modeling behind those predictions. They just joke that they are often wrong. Today, people seem genuinely interested in what's behind COVID-19 predictions and whether they agree with those predictions. Let's take to task the news and how it's reporting these predictions. Estimates should be reported with the error in those predictions. Let's take to task the politicians who are selectively using models, or discrediting modeling as a scientific endeavor [8], to serve their own agenda or political views. As modelers we need to remain vigilant in these times because the work being done 
is important. Modeling matters and how we use and report those models matter too.

\section{References}

1. Centers for Disease Control and Prevention COVID-19 Forecasts. https://www.cdc.gov/coronavirus/2019-ncov/covid-data/forecast ing-us.html

2. Mariano W, Trubey JS (2020) 'It's just cuckoo': state's latest data mishap causes critics to cry foul. Atlanta Journal Constitution. https://www.ajc.com/news/state-regional-govt-politics/justcuckoo-state-latest-data-mishap-causes-critics-cry-foul/182PpU vUX9XEF8vO11NVGO/. Accessed 13 May 2020

3. Yglesias M (2020) The Trump administration's "cubic model" of coronavirus deaths, explained. Vox.com. https://www.vox.com/ 2020/5/8/21250641/kevin-hassett-cubic-model-smoothing. Accessed 8 May 2020

4. Glanz J, Robertson C (2020) Lockdown delays cost at least 36,000 lives, data show. New York Times. https://www.nytimes.com/ 2020/05/20/us/coronavirus-distancing-deaths.html?action=click\& module $=$ Spotlight \&pgtype $=$ Homepage. Accessed 20 May 2020

5. Pei S, Kandula S, Shaman J (2020) Differential effects of intervention timing on COVID-19 spreading the United States. MedRxiv preprint. https://www.medrxiv.org/content/10.1101/ 2020.05.15.20103655v1.full.pdf

6. Begley S (2020) Influential Covid-19 model uses flawed methods and shouldn't guide U.S. policies, critics say. CNBC.com. https:// www.cnbc.com/2020/04/17/influential-covid-19-model-usesflawed-methods-and-shouldnt-guide-us-policies-critics-say.html. Accessed 17 Apr 2020

7. McCarthy A (2020) COVID-19 projection models are proving to be wrong. National Review. https://www.nationalreview.com/ corner/coronavirus-pandemic-projection-models-proving-unreli able/. Accessed 9 Apr 2020

8. Sen NS (20202) Cornyn steps in it again, tweeting that data modeling isn't part of the scientific process. San Antonio Current. https://www.sacurrent.com/the-daily/archives/2020/04/15/sen-cor nyn-steps-in-it-again-tweeting-that-data-modeling-isnt-part-of-thescientific-process. Accessed 15 Apr 2020

Publisher's Note Springer Nature remains neutral with regard to jurisdictional claims in published maps and institutional affiliations. 